\title{
Intraspecific macroscopic digestive anatomy of ring-tailed lemurs (Lemur catta), including a comparison of frozen and formalin-stored specimens
}

\author{
Marcus Clauss $^{1}{ }^{10}$. Jelscha Trümpler ${ }^{1} \cdot$ Nicole L. Ackermans ${ }^{1,8} \cdot$ Andrew C. Kitchener $^{2} \cdot$ Georg Hantke $^{2}$. \\ Julia Stagegaard ${ }^{3} \cdot$ Tomo Takano $^{4} \cdot$ Yuta Shintaku ${ }^{4} \cdot$ Ikki Matsuda $^{4,5,6,7}$
}

Received: 16 July 2020 / Accepted: 29 October 2020 / Published online: 12 November 2020

(C) The Author(s) 2020

\begin{abstract}
Digestive tract measurements are often considered species specific, but little information exists on the degree to which they change during ontogeny within a species. Additionally, access to anatomical material from nondomestic species is often limited, with fixed tissues possibly representing the only available source, though the degree to which this material is representative in terms of dimensions and weight is debatable. In the present study, the macroscopic anatomy of the digestive tract (length of intestinal sections, and tissue weights of stomach and intestines) of 58 Lemur catta [ranging in age from 1 month (neonates) to 25 years], which had been stored frozen $(n=27)$ or fixed in formalin $(n=31)$, was quantified. Particular attention was paid to the caecum and the possible presence of an appendix. The intraspecific allometric scaling of body mass $(\mathrm{BM})^{0.46[0.40 ; 0.51]}$ for total intestine length and $\mathrm{BM}^{0.48[0.41 ; 0.54]}$ for small intestine length was higher than the expected geometric scaling of $\mathrm{BM}^{0.33}$, and similar to that reported in the literature for interspecific scaling. This difference in scaling is usually explained by the hypothesis that, to maintain optimal absorption, the diameter of the intestinal tube cannot increase geometrically. Therefore, geometric volume gain of increasing body mass is accommodated for by more-than-geometric length scaling. According to the literature, not all L. catta have an appendix. No appendix was found in the specimens in the present study. The proportions of length measurements did not change markedly during ontogeny, indicating that the proportions of the foetus are representative of those of the adult animal. By contrast, width and tissue-mass scaling of the caecum indicated disproportionate growth of this organ during ontogeny that was not reflected in its length. Compared to overall intraspecific variation, the method of storage (frozen vs. formalin) had no relevant impact on length or weight measurements.
\end{abstract}

Keywords Anatomy $\cdot$ Allometry $\cdot$ Digestive tract $\cdot$ Primates $\cdot$ Strepsirrhini

\section{Introduction}

Based on geometric considerations, volume measurements should scale isometrically (in other words, linearly) with body mass, surface measurements should scale to body mass to the power of 0.67 , and length measurements—-such as those of intestinal tract sections-should scale to body mass to the power of 0.33 (Calder 1996; Clauss and Hummel

Electronic supplementary material The online version of this article (https://doi.org/10.1007/s10329-020-00873-8) contains supplementary material, which is available to authorized users.

Marcus Clauss

mclauss@ vetclinics.uzh.ch

Extended author information available on the last page of the article
2005). Scaling relationships that are not isometric (or linear) are typically called 'allometric' (verbatim translation: 'another measure'), and there is a certain tradition to equate 'allometric scaling' with 'geometric scaling,' so that 'positive allometry' indicates a higher exponent than expected due to geometric rules.

In contrast to the expected geometric scaling of length measurements, several studies found a higher scaling exponent (positive allometry) for interspecific scaling relationships of various intestinal section lengths with body mass in mammals (Woodall and Skinner 1993; Lavin et al. 2008; McGrosky et al. 2016, 2019a, b). The common explanation for this observation, developed to our knowledge by Woodall and Skinner (1993), is that on the one hand, both intestinal volume and surface area (calculated from length and circumference measurements in their study) do indeed scale 
geometrically with body mass, but that intestinal diameter scales to a lower exponent in order to maintain short diffusion distances from the lumen to the secretory and absorptive surfaces. Therefore, the length of the intestine must scale more-than-geometrically (with positive allometry) to accommodate geometric volume and surface scaling. If this reasoning were correct, we would expect similar scaling at the intraspecific level across ontogeny, particularly because the transition from milk to any other diet likely implies a decrease in diet digestibility, theoretically making short distances between the lumen and surface all the more relevant.

On a completely different level of consideration, anatomical material from nondomestic species can be hard to come by, but data derived from it are important for comparative studies with a physiological as well as an evolutionary focus (e.g., Lavin et al. 2008; Smith et al. 2017). Historically, macroanatomical studies often relied on comparatively older literature [Crile and Quiring (1940); cf. the instructive example given by Ridgway and Van Alstyne (2017)]. Given that hunting expeditions or culling operations are no longer socially acceptable, the accumulation of samples typically depends on the storage of deceased individuals collected as single specimens from zoological collections, or during fieldwork. Typically, these specimens are either stored frozen or fixed in formalin. Compared to frozen storage of fresh material, storage in formalin often leads to tissue shrinkage (Lentle et al. 1997); comparisons of intestine length measurements between frozen and formalin-fixed material of a limited number of specimens indicated some degree of shortening during formalin storage (Hume et al. 1993). More recently, a comparative study in humans, in which intestine length was measured during abdominal surgery in live patients and at dissection in formalin-fixed cadavers, indicated significantly shorter intestine length for the latter; the length measures for the fixed specimens were also shorter than those reported for freshly dissected cadavers in the literature (Zhou et al. 2020). Evidently, published results allow for the possibility that shrinkage occurs after death, irrespective of the method of storage used. For example, studies on skin samples indicated that tissue shrinkage occurred as an effect of excision and was not exacerbated by formalin storage (Dauendorffer et al. 2009), and Parker (1963) found that fish shrank shortly after killing, irrespective of the preservation method, without additional effects of longer storage. For intestines, both the effects of relaxation-elongation and of contraction-shortening after death have been reported in the literature (Zhou et al. 2020). An older comprehensive study in dogs documented that intestinal shortening of fresh material occurred within the first few hours after death (Nickel 1933). This shortening sometimes persisted, but was more often followed by relaxation that exceeded the effects of shortening within $48 \mathrm{~h}$, leading to longer-than-life measurements at this timepoint that were considered to represent the relaxation of the natural tonus of the smooth intestinal musculature (Nickel 1933). These findings add to the overall uncertainty concerning intestinal length measurements, and indicate that the effects of storage and fixation depend on the state of the material at the moment of fixation or freezing. There are most likely many other factors, such as whether material is frozen or fixed with or without the mesenteries, the temperature at dissection, or the forces involved in laying out an intestinal section in a straight line for measurement (Underhill 1955), that could also influence the final outcome.

In the present study, we used the opportunity to access three different collections of gastrointestinal tracts of ringtailed lemurs (Lemur catta), either preserved frozen attached to the mesenteries, or preserved in formalin after dissection of the mesenteries. The main aims of the study were to test whether intraspecific allometries of intestinal lengths resembled those reported for interspecific comparisons in other mammals, and whether a systematic difference between the two preservation methods could be detected. In addition, we aimed to investigate whether the prominence of the caecum, the site of microbial fermentation of complex carbohydrates derived from plant fibre (Campbell et al. 2000), changed with ontogeny from milk-dependent neonates to mature individuals. Ring-tailed lemurs have been described as a species in which a caecal appendix may occur variably (Smith et al. 2013, 2017), although macroscopic descriptions of the caecum did not indicate the presence of an appendix (Campbell et al. 2000; McGrosky et al. 2019b). Therefore, special attention was given to the appearance of the apex of the caecum.

\section{Methods}

Three different collections of ring-tailed lemur specimens (Lemur catta; $n=58$ ) were available for this study (Table 1 ). The first consisted of 12 specimens from various zoological collections, stored frozen as whole carcasses for varying amounts of time, and thawed and dissected for the present study. The second set consisted of 15 specimens of a large family group originating from a single zoological facility; the gastrointestinal tract of each animal, including all mesenteries, had been excised immediately after death and stored frozen (for 12 months) until dissection. The third set consisted of 31 specimens from a single zoological collection, where the gastrointestinal tract had been dissected from freshly deceased specimens, freed of mesenteries to varying degrees, partially opened (lengthwise), and stored in formalin for varying amounts of time. The body mass of 18 of the animals surpassed the range of mean body mass, $2-2.5 \mathrm{~kg}$, reported for adult free-living ring-tailed lemurs (Sussman 1991; Drea and Weil 2008), yet our age-body mass graph 
Table 1 Overview of the three sets of gastrointestinal tracts (GIT) of Lemur catta used in the present study

\begin{tabular}{|c|c|c|c|c|c|}
\hline Collection & Origin & $n$ (females, males) & Age range & Body mass range $(\mathrm{kg})$ & Preservation method \\
\hline A & Various zoological collections & $12(7,5)$ & Neonate-24 years & $0.07-3.48$ & $\begin{array}{l}\text { Whole carcasses, stored frozen (for } \\
3-20 \text { years), thawed and dissected } \\
\text { for the present study }\end{array}$ \\
\hline B & Single zoological collection & $15(6,9)$ & $0.1-16$ years & $0.57-2.67$ & $\begin{array}{l}\text { GIT, including mesenteries, dis- } \\
\text { sected directly after death, stored } \\
\text { frozen for } 1 \text { year, thawed and } \\
\text { prepared for the present study }\end{array}$ \\
\hline $\mathrm{C}$ & Single zoological collection & $31(19,12)$ & $0.33-25$ years & $0.73-2.85$ & $\begin{array}{l}\text { GIT dissected after death, freed } \\
\text { of mesenteries, partially } \\
\text { opened, stored in formalin (for } \\
1-60 \text { years) }\end{array}$ \\
\hline
\end{tabular}

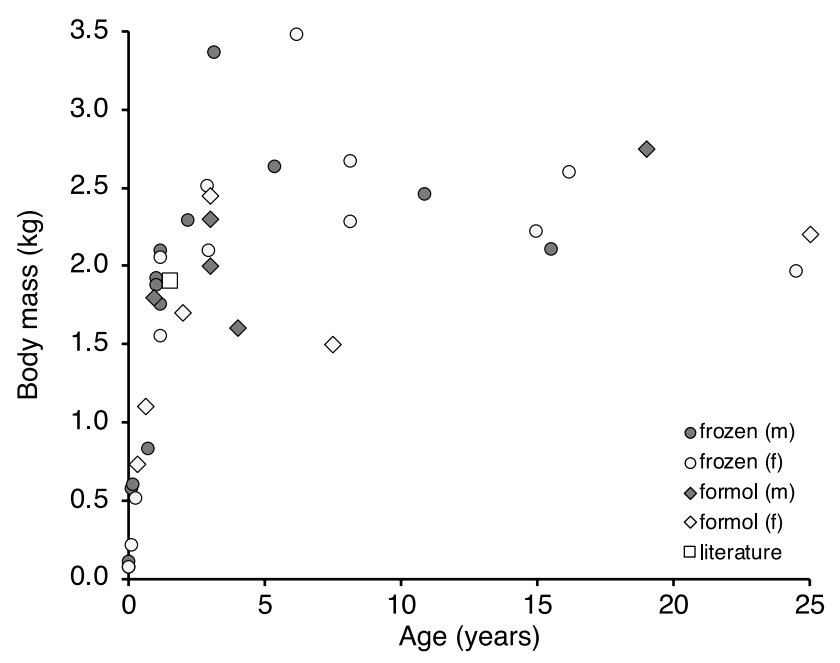

Fig. 1 Relationship of body mass and age in male $(m)$ and female (f) ring-tailed lemurs (Lemur catta) for which age was known in the present study, and for which the intestine was stored frozen or in formalin (formal). Note two particularly heavy animals with a body mass $>3 \mathrm{~kg}$, which were excluded from subsequent analyses

(Fig. 1) largely resembled that given by Koyama et al. (2008; adult body masses between 2 and $3 \mathrm{~kg}$ ), and only two animals appeared to be of excessive weight for their age, being distinctively heavier than the maximum weight, $2.6 \mathrm{~kg}$, recorded for ring-tailed lemurs in their natural habitat by Simmen et al. (2010). These findings suggested that obesity was not a major factor in the study populations, and only the two heaviest animals were excluded from the analyses.

All gastrointestinal tracts were freed from mesenteries and adhering adipose tissue and photographed (Fig. 2). For photography and measurements, thawed intestines were laid out without deliberate stretching beyond that countered by the friction between the intestine and the metal dissection table. Intestines preserved in formalin were gently straightened for length measurements. Length measurements included those of the small intestine, the caecum, and the colon and rectum combined. In thawed (unopened), but not in formalin-preserved (and generally opened) caeca, the width at the base was measured as well. Because of its nontubular structure and the corresponding greater difficulty in defining a line of measurement, the length of the stomach was not measured. Subsequently, the stomach, small intestine, caecum and the joined colon-rectum were cleared of contents, blotted dry with paper towels, and weighed.

Statistical evaluations were performed in R ( $\mathrm{R}$ Core Team 2017). Linear models based on log-transformed data were used. First, we tested the allometric relationships of all intestine lengths, caecum width and weights with body mass. Additionally, the effect of body mass on organ measurements expressed as percentage of either total intestinal length or total gastrointestinal tract (GIT) tissue weight was assessed in the same manner, to test whether changes in the prominence of organs occurred with maturation. These results are given to facilitate comparison with other allometries, even though residuals of the models were mostly not normally distributed. Then, the linear models were repeated using ranked data for quantitative intestine measures and body mass (making the models non-parametric), with the additional co-factors sex and preservation method (frozen or fixed) and their interaction. Whether body mass was a significant covariable in these secondary models or not was identical to whether the scaling exponent was significant in the primary models, and is therefore not indicated separately. The significance level was set to 0.05 . For graphical representation, untransformed data are shown.

\section{Results}

The macroscopic appearance of the ring-tailed lemur digestive tract in the present study resembled that described by Campbell et al. (2000) and McGrosky et al. (2019b), with a simple stomach, an elongated and haustrated caecum, and a proximal colon with some haustration (Fig. 2). Although inspection of the caecum indicated that some individuals might have a caecal appendix (e.g., Fig. 2c), when the apex 

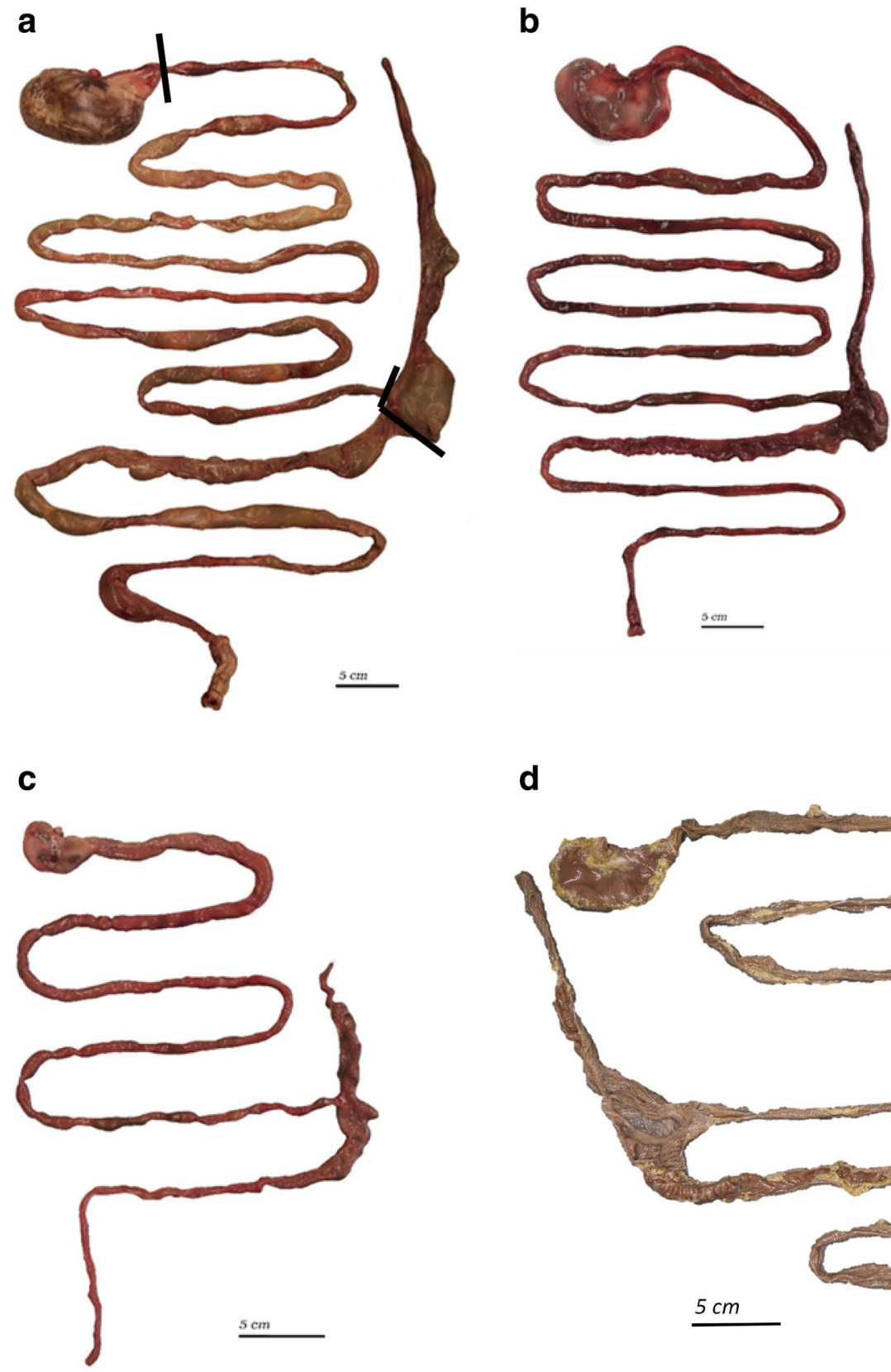

d

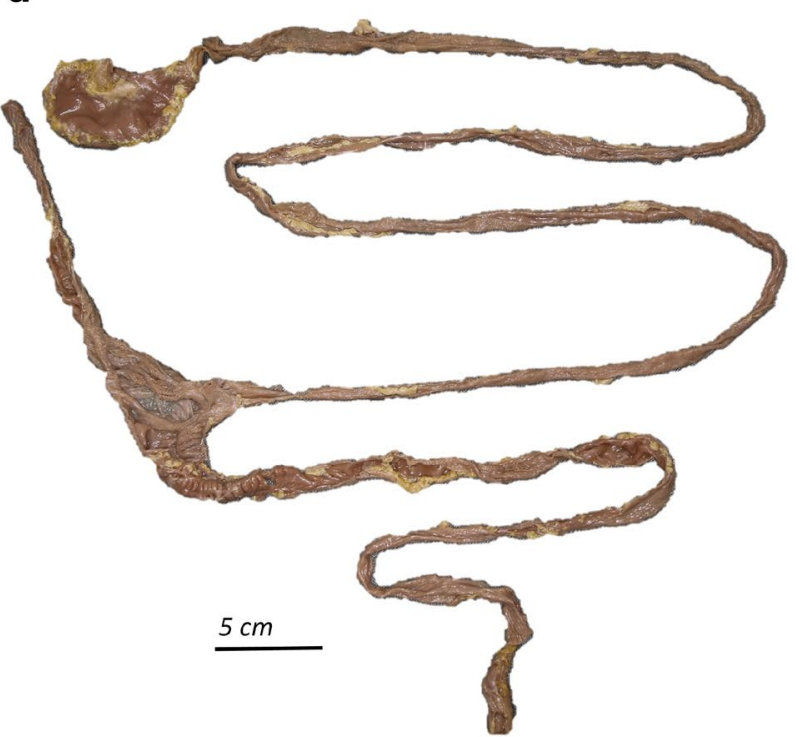

Fig. 2 Gastrointestinal tracts (GIT) of various ring-tailed lemurs ( $L$. catta) stored frozen $(\mathbf{a}-\mathbf{c})$ or in formalin $(\mathbf{d})$ : 16.2-year-old female, body mass $2.6 \mathrm{~kg}$ (a); 8.2-year-old female, body mass $2.3 \mathrm{~kg}$ (b);

of the caecum was opened, no different section could not be discerned that resembled a lymphatic organ (Fig. 3).

The measurements taken in the present study were within a range that included those of an individual published by Campbell et al. (2000) (Fig. 4) except for the caecum, for which these authors reported a greater length. The allometric scaling of length measures of all intestinal sections yielded exponents with $95 \%$ confidence intervals above the 0.33 0.1-year-old male, body mass $0.6 \mathrm{~kg}$ (c); adult female, body mass $2.1 \mathrm{~kg}(\mathbf{d})$. a Measurement borders for the small intestine, caecum and colon indicated by black lines

scaling exponent expected from geometry (i.e., there was positive allometry) (Table 2). The scaling exponent of caecum width was particularly high at 0.57 . The relative length of the intestinal sections did not change with body mass, suggesting that their proportions (small intestine 59\%, caecum $8 \%$, colon and rectum $32 \%$ of the total intestinal length) remain stable during ontogeny (Table 2; Fig. 5a). Preservation method only had an effect on the length of the colon 


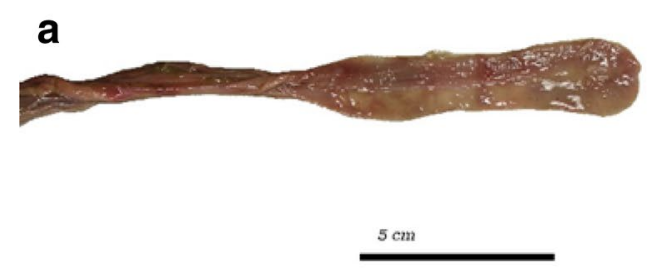

C

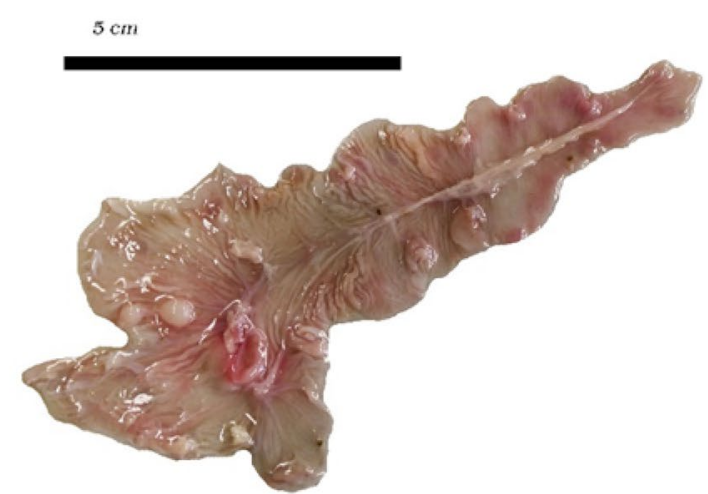

Fig. 3 The opened caecum (apex pointing towards the right) of various ring-tailed lemurs ( $L$. catta) stored frozen $(\mathbf{a}-\mathbf{c})$ or in formalin $(\mathbf{d})$ indicating the absence of a caecal appendix: 16.2-year-old female,

and rectum, which were longer for specimens preserved in formalin, but the results also indicated an interaction that suggested that the effect of preservation method differed according to sex (Table 2; Fig. 4c). Samples fixed in formalin had a slightly longer relative colon and rectum length $(34 \pm 4 \%$ vs. $30 \pm 4 \%)$ and a shorter relative small intestine length ( $57 \pm 4 \%$ vs. $62 \pm 5 \%)$ (Table 2$)$.

The body-mass scaling exponents for organ masses exceeded an isometric (or linear) scaling in their 95\% confidence intervals, except for the stomach (Table 3). Of the intestine sections, the small intestine showed the least distinct deviation (exponent confidence interval 1.01; 1.28), and the caecum $(1.21 ; 1.54)$ the most distinct deviation from isometry (linearity). As for length measures, preservation status had an effect on caecum and colon and rectum tissue mass (Table 3). Therefore, total intestinal mass and total GIT mass were slightly higher in formalin-fixed specimens (Table 3). Considering the entire GIT, the relative mass of the small intestine and colon \& rectum did not vary with body mass; by contrast, the relative mass of the stomach declined, and that of the caecum increased, with body mass (Table 3; Fig. 5b). Considering only the intestinal tract, relative caecum mass increased with body mass (Table 3 ). Relative tissue mass of the colon and rectum of the total GIT was higher in formalin-fixed specimens (frozen: $27 \pm 7 \%$; fixed $35 \pm 6 \%$ of total GIT mass) (Table 3 ). b
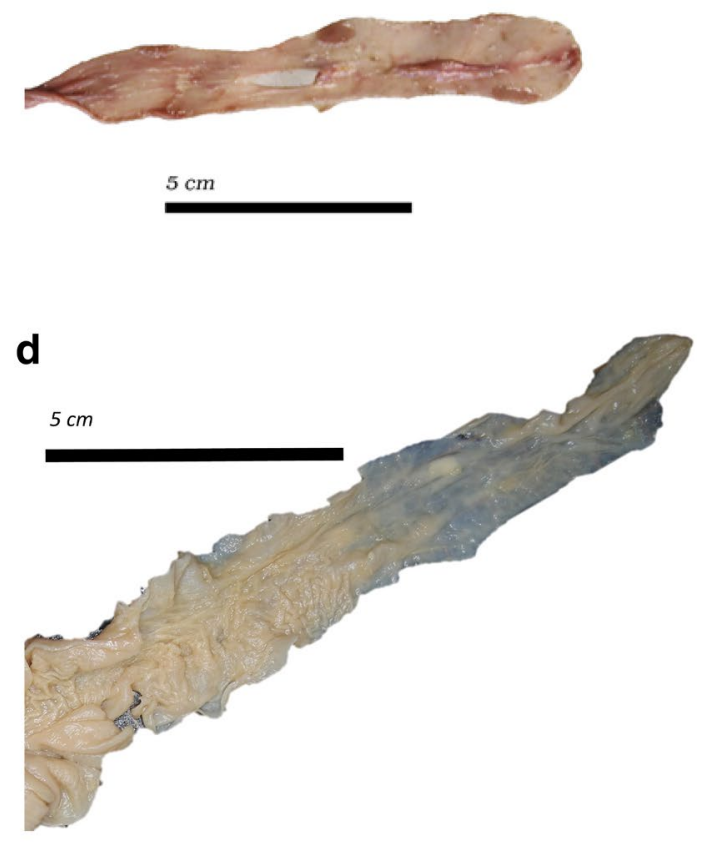

body mass $2.6 \mathrm{~kg}$ (see Fig. 2a) (a); 3.2-year-old male, body mass $3.4 \mathrm{~kg}$ (b); 0.1-year-old male, body mass $0.6 \mathrm{~kg}$ (see Fig. 2c) (c); adult female, body mass $1.5 \mathrm{~kg}(\mathbf{d})$

\section{Discussion}

The results of the present study are of relevance to both methodological and biological aspects of digestive tract anatomy, and for compilations of large comparative datasets. The data indicate substantial intraspecific variation in intestinal measurements within mature specimens of $L$. catta. For example, Fig. $4 \mathrm{~d}$ indicates that at a body mass of $2 \mathrm{~kg}$, the length of the intestinal tract in ring-tailed lemurs may vary by $1 \mathrm{~m}$. In humans, at evidently higher body masses, the documented variation in small intestine length can exceed $4 \mathrm{~m}$ (reviewed in Zhou et al. 2020). A large body of literature documents intraspecific variation in intestinal length in rodents due to diet and/or energetic constraints, and intraspecific intestinal length flexibility has been linked to the number of different habitats small rodent species can occupy (reviewed in Naya et al. 2008). For large mammals no corresponding compilations of data exist. To date, variations in digestive anatomy as described for humans, or the lemurs in the present study, remain largely unexplained; however, the variations are of such a magnitude that interobserver error appears a very unlikely cause. In the lemurs studied here, effects of diet or different husbandry conditions also appear unlikely. Thus, the variation remains unexplained. While such variation may not be a systematic problem for largescale comparisons of intestinal length (Woodall and Skinner 

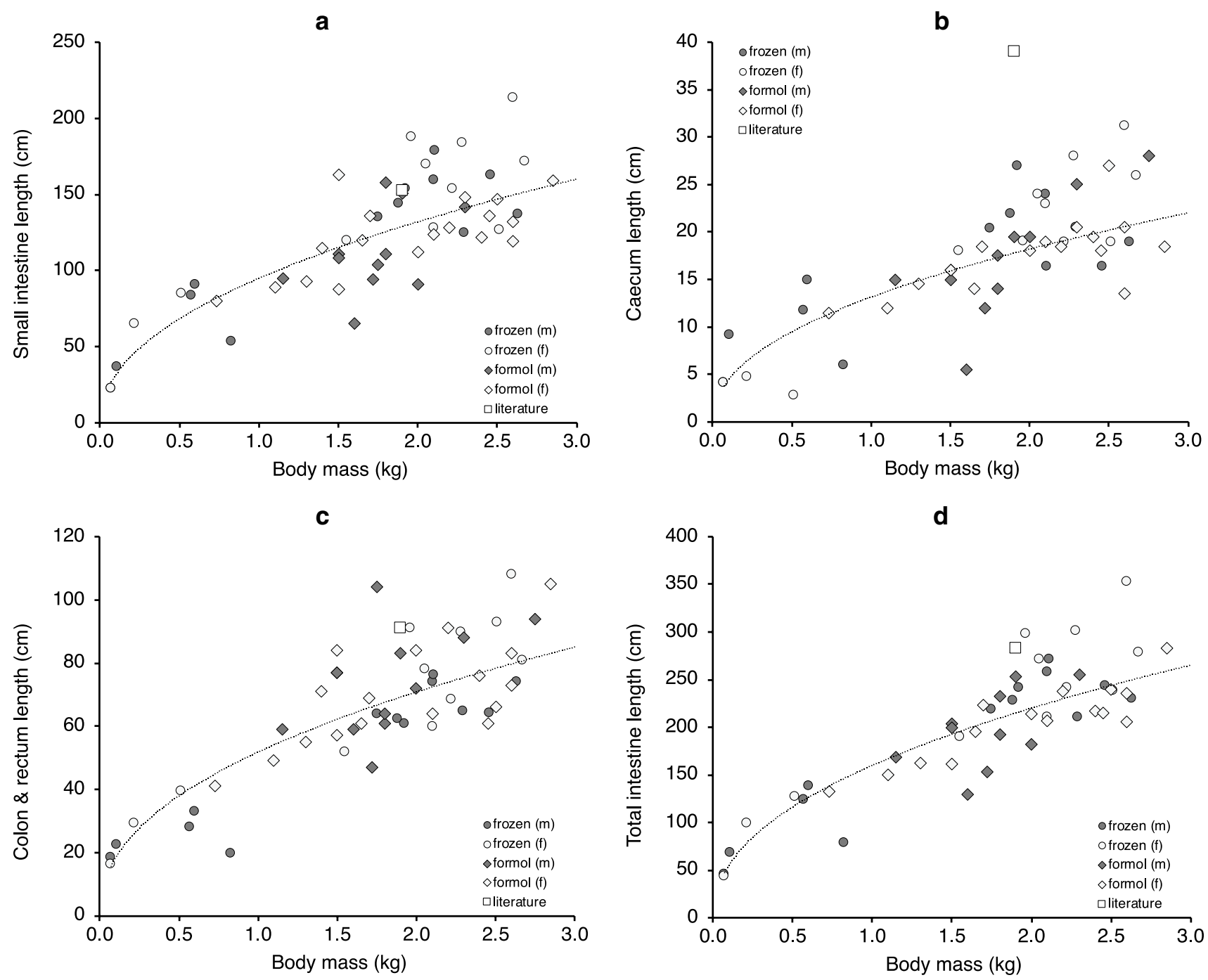

Fig. 4 Relationship between body mass and a small intestine length, b caecum length, c colon and rectum length, and $\mathbf{d}$ total intestine length in ring-tailed lemurs ( $L$. catta) in the present study (males

1993; Lavin et al. 2008; Lovegrove 2010), studies exploring quantitative differences between only a few specimens of a few species need to take this variation into account and should include a sufficient number of individuals.

Given the magnitude of this general intraspecific variation, the variation introduced by the use of formalin-fixed material appeared to be of a negligible magnitude in the present study. The material that was compared had either been frozen at an unknown time (but most likely within $24 \mathrm{~h}$ ) after death, then thawed and dissected from the mesenteries, or dissected at an unknown time after death and subsequently placed in formalin. Of the two processes, freezing and thawing could be assumed to counteract any potential effect of post-mortem contraction. By contrast, formalin fixation could theoretically have occurred at any stage of post-mortem contraction or relaxation, and

and females, preserved frozen or in formalin) and in an individual reported by Campbell et al. (2000) (literature). For statistical analysis, see Table 2

therefore, shorter dimensions, on average, could have been expected for this method. However, the opposite was the case, with formalin-fixed specimens showing somewhat longer large intestines (Table 2). One theoretical explanation for this could be the lengthwise opening of the intestines, which would not have affected the length of the smooth-walled small intestine, but may have had an effect on the haustration of the large intestine: when opened, the haustra might not constrain the length of the organ as much as they do in a closed state. Unfortunately, this finding only became evident after the frozen/thawed material had been disposed of, otherwise a comparison of the length of the same material with the intestine closed and opened could have been performed. However, the formalin-fixed large intestines were also heavier-longitudinal cuts should not affect mass measurements-suggesting 
Table 2 Allometric regressions ( $y=a$ body mass $\left.{ }^{b}\right)$ and 95\% confidence intervals $(C I)$ for measures of intestinal lengths of ring-tailed lemurs $(L$. catta) according to sex and preservation method

\begin{tabular}{|c|c|c|c|c|c|c|c|}
\hline Dependent variable $(y)$ & $a(95 \% \mathrm{CI})$ & $P$ & $b(95 \% \mathrm{CI})$ & $P$ & $\operatorname{Sex}^{\mathrm{a}}$ & Preservation $^{\mathrm{a}}$ & Interaction $^{\mathrm{a}}$ \\
\hline \multicolumn{8}{|l|}{ Absolute length $(\mathrm{cm})$} \\
\hline Small intestine & $95(89,101)$ & $<0.001$ & $0.48(0.41,0.54)$ & $<0.001$ & n.s. & n.s. & n.s. \\
\hline Caecum $^{\text {b }}$ & $13(12,14)$ & $<0.001$ & $0.47(0.37,0.58)$ & $<0.001$ & n.s. & n.s. & n.s. \\
\hline Colon and rectum ${ }^{\mathrm{b}}$ & $52(49,55)$ & $<0.001$ & $0.45(0.38,0.52)$ & $<0.001$ & (+) 0.033 & (+) 0.006 & 0.028 \\
\hline Total intestine ${ }^{\mathrm{b}}$ & $160(152,168)$ & $<0.001$ & $0.46(0.40,0.51)$ & $<0.001$ & n.s. & n.s. & n.s. \\
\hline Caecum width & $2.1(1.9,2.4)$ & $<0.001$ & $0.57(0.47,0.67)$ & $<0.001$ & n.s. & - & - \\
\hline \multicolumn{8}{|c|}{ Relative length (\% total intestinal length) } \\
\hline Small intestine & $59(58,61)$ & $<0.001$ & $0.01(-0.01,0.04)$ & 0.282 & n.s. & n.s. & n.s. \\
\hline Caecum $^{\mathrm{b}}$ & $8(8,9)$ & $<0.001$ & $0.01(-0.09,0.10)$ & 0.913 & n.s. & n.s. & n.s. \\
\hline Colon and rectum & $32(30,33)$ & $<0.001$ & $-0.01(-0.06,0.03)$ & 0.568 & n.s. & (+) 0.014 & n.s. \\
\hline
\end{tabular}

Body mass in kilograms. Plus sign in parentheses indicates higher values in females, or higher values in formalin-preserved tissues n.s. Not significant

${ }^{a}$ Results of additional models testing for effects of sex and preservation using ranked data

${ }^{\mathrm{b}}$ Residuals were not normally distributed

a

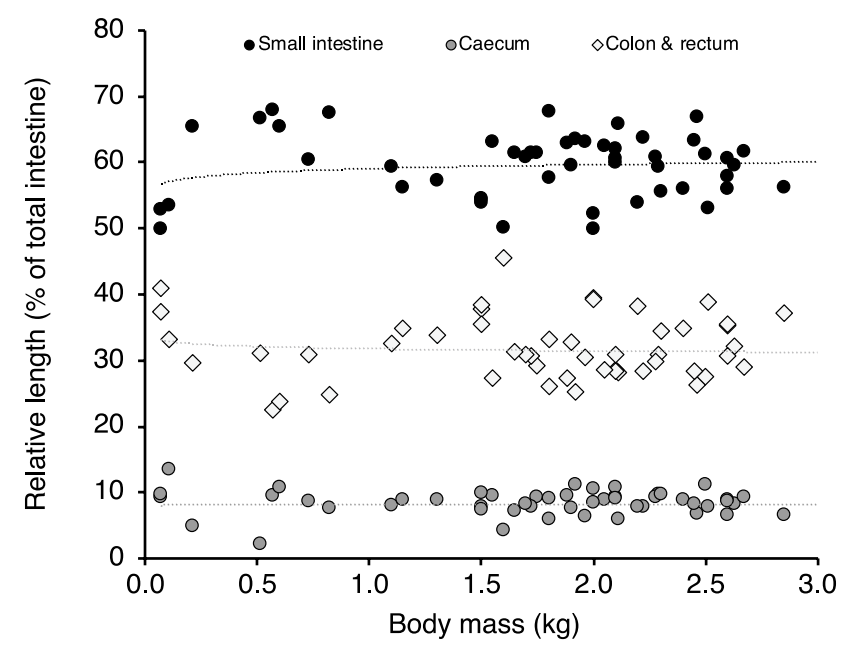

b

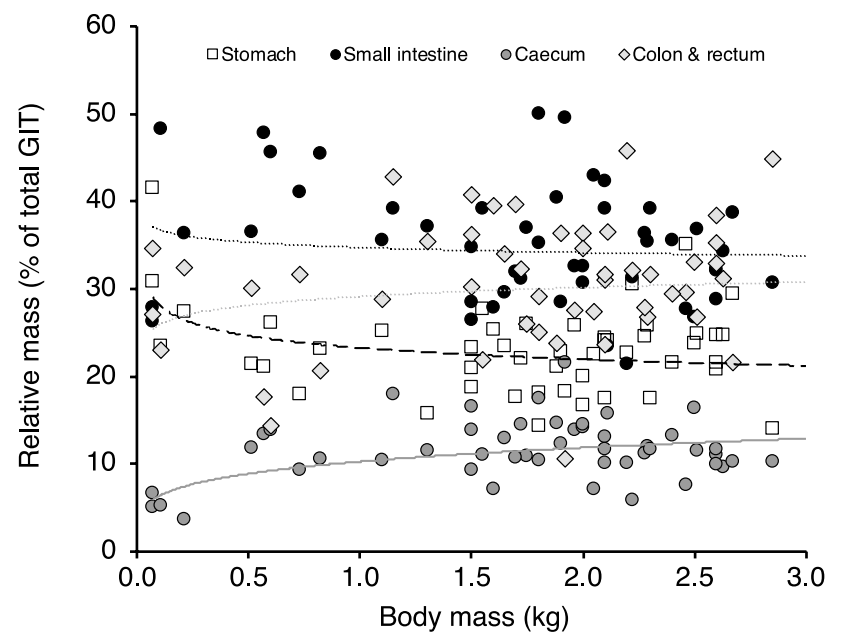

Fig. 5 Relationship of body mass and a relative intestine lengths, b relative gastrointestinal organ masses (both in \% of total) of ring-tailed lemurs (L. catta) in the present study. The only significant relationships are those for the relative mass of stomach and caecum (cf. Table 3)

that this difference between the preservation methods for the large intestine might simply have been due to chance.

Overall, the fact that intraspecific variability was of a magnitude that rendered the effect of preservation secondary suggests that, for large-scale comparisons, data from both conservation methods should be acceptable. It should be noted that our study does not represent an experimental approach to preservation methods, where the same material is measured repeatedly after exposure to different treatments, or material from the same facility exposed to different treatments. Most particularly, the present study did not include intact carcasses preserved in formalin with the gastrointestinal tract in situ. Under that condition, shorter measurements might be expected (Zhou et al. 2020). By contrast, preserving intestinal material in formalin after exenteration (and removal of mesenteries), as done in one of the facilities of the present study, does not appear to lead to a systematic deviation in macroanatomical measures, and therefore represents a suitable way of preserving intestines for long periods of time.

Regardless of the large variation in intestinal measures in mature specimens, the intraspecific allometry, including that of neonates and juveniles, yielded scaling relationships comparable to those previously reported in the literature in 
Table 3 Allometric regressions for weight measurements ( $y=a$ body mass $\left.{ }^{b}\right)$ including $95 \%$ confidence intervals for tissue mass of GIT of ringtailed lemurs (L. catta) according to sex and preservation method

\begin{tabular}{|c|c|c|c|c|c|c|c|}
\hline Dependent variable $(y)$ & $a(95 \% \mathrm{CI})$ & $P$ & $b(95 \% \mathrm{CI})$ & $P$ & $\operatorname{Sex}^{\mathrm{a}}$ & Preservation $^{\mathrm{a}}$ & Interaction $^{\mathrm{a}}$ \\
\hline \multicolumn{8}{|l|}{ Absolute mass (g) } \\
\hline Stomach $^{\mathrm{b}}$ & $6.9(6.2,7.8)$ & $<0.001$ & $1.08(0.95,1.20)$ & $<0.001$ & n.s. & n.s. & n.s. \\
\hline Small intestine ${ }^{\mathrm{b}}$ & $10.5(9.3,11.9)$ & $<0.001$ & $1.14(1.01,1.28)$ & $<0.001$ & n.s. & n.s. & n.s. \\
\hline Caecum $^{\mathrm{b}}$ & $3.0(2.6,3.6)$ & $<0.001$ & $1.37(1.21,1.54)$ & $<0.001$ & n.s. & (+) 0.048 & n.s. \\
\hline Colon and rectum ${ }^{\mathrm{b}}$ & $9.0(7.7,10.6)$ & $<0.001$ & $1.22(1.05,1.39)$ & $<0.001$ & n.s. & (+) 0.002 & n.s. \\
\hline Total intestine ${ }^{b}$ & $22.8(20.1,25.9)$ & $<0.001$ & $1.20(1.06,1.33)$ & $<0.001$ & n.s. & $(+) 0.017$ & n.s. \\
\hline Total GIT ${ }^{\mathrm{b}}$ & $29.8(26.4,33.7)$ & $<0.001$ & $1.17(1.04,1.30)$ & $<0.001$ & n.s. & (+) 0.027 & n.s. \\
\hline \multicolumn{8}{|c|}{ Relative mass ( $\%$ total GIT mass) } \\
\hline Stomach & $23(22,25)$ & $<0.001$ & $-0.08(-0.15,-0.02)$ & 0.014 & n.s. & n.s. & n.s. \\
\hline Small intestine & $34(33,37)$ & $<0.001$ & $-0.02(-0.09,0.04)$ & 0.458 & n.s. & n.s. & n.s. \\
\hline Caecum $^{\mathrm{c}}$ & $10(9,11)$ & $<0.001$ & $0.21(0.12,0.30)$ & $<0.001$ & n.s. & n.s. & n.s. \\
\hline Colon and rectum & $29(27,32)$ & $<0.001$ & $0.05(-0.03,0.14)$ & 0.244 & n.s. & $(+) 0.008$ & n.s. \\
\hline \multicolumn{8}{|c|}{ Relative mass ( $\%$ total intestine mass) } \\
\hline Small intestine & $46(43,48)$ & $<0.001$ & $-0.05(-0.11,0.00)$ & 0.069 & n.s. & (-) 0.019 & n.s. \\
\hline Caecum $^{c}$ & $13(12,15)$ & $<0.001$ & $0.18(0.09,0.26)$ & $<0.001$ & n.s. & n.s. & n.s. \\
\hline Colon and rectum ${ }^{\mathrm{b}}$ & $38(35,41)$ & $<0.001$ & $0.02(-0.07,0.11)$ & 0.657 & n.s. & n.s. & n.s. \\
\hline
\end{tabular}

Body mass in kilograms. Plus sign in parentheses indicates higher values in females, or higher values in formalin-preserved tissues

${ }^{a}$ Results of additional models testing for effects of sex and preservation using ranked data

${ }^{\mathrm{b}}$ Residuals were not normally distributed

${ }^{\mathrm{c} B o d y}$ mass was not significant in the ranked-data model

interspecific studies (see "Introduction"), in the range of a $0.4-0.5$ scaling exponent. A similar, more-than-geometric (or positively allometric) intraspecific scaling of the small and the large intestine across ontogeny was demonstrated in rats (Toloza and Diamond 1992) and mice (Wołczuk et al. 2011). As in the ring-tailed lemurs examined here, the scaling effect was mostly found in the neonate and juvenile stages, and was not evident within mature specimens. The more-than-geometric scaling of intestinal lengths, as explained in the Introduction, appears to be a general feature of mammalian macroanatomy.

In ruminants and possibly other foregut fermenters, the change in proportions of the different GIT sections during the transition from milk-feeding to weaning are very distinct. Indeed, the fermentation compartments increase disproportionately in tissue weight (e.g., Wardrop and Coombe 1960; Godfrey 1961) and, by inference, in volume. In horses, the length proportions of the caecum and proximal colon-which represent the fermentation chambers-similarly increase with age until maturity (Smyth 1988). For the ring-tailed lemurs of the present study, a similar ontogenetic change in GIT proportions linked to a change in diet was not evident in the length measurements.

The scaling of organ tissue masses surprisingly appeared more-than-linear (or, again, showed positive allometry), with 95\% confidence intervals of the scaling exponent consistently above 1.00 (Table 3 ). To our knowledge, no recent comprehensive treatise on interspecific gastrointestinal tissue mass exists. Calder (1996) cites the scaling in 41 mammal species established by Brody (1945) with an exponent of 0.94; using the SE for the exponent given in the original study by Brody (1945), the $95 \%$ confidence interval of that exponent includes linearity at $0.85-1.03$ (and is nearly identical for the exponent found for birds in that study). In the original data from Navarrete et al. (2011) for 100 mammal species, a similar scaling exponent with a confidence interval of $0.88-0.94$ can be calculated, and Prothero (2015) found a scaling exponent of 0.93 in mammals that also excluded linearity in the confidence interval. Why mammalian and avian GIT scaling should be slightly less-than-linear has not been explained so far, and we are also unable to offer an explanation for this. We hypothesize that the more-than-linear scaling found in our data is an intraspecific effect of ontogeny, reflecting the shift from milk feeding to solid food. In the case of the ring-tailed lemur, the natural diet comprises fruits, leaves and other plant parts (e.g., Rasamimanana and Rafidinarivo 1993; Simmen et al. 2006). On the one hand, an increasing tissue mass with age could derive from a disproportionately increased muscle mass as an effect of processing solid material. On the other hand, it could derive in particular from absorptive mucosa development in those compartments (caecum, colon) where fermentative digestion intensifies after the switch to solid food. The 
enhancing effect of short-chain fatty acids, the main products of microbial fermentation, on gut mucosa development-and hence tissue mass-is well known (e.g., Kripke et al. 1989). Fermentative microbial digestion has been suggested for ring-tailed lemurs (Campbell et al. 2000), and was demonstrated by the measurement of short-chain fatty acids in the faeces of captive specimens (McKenney et al. 2018). Correspondingly, the scaling exponent of tissue mass was highest for the caecum, followed by the colon and rectum, whereas the small intestine only scaled slightly higher than linearly, and the stomach scaling was linear (Table 3). A shift in the faecal microbiome with the transition from milk-feeding to weaning has been demonstrated in lemurs, including ring-tailed lemurs (McKenney et al. 2018), which would be expected to parallel the increase in tissue mass.

No evidence was found in the present study for the presence of a caecal appendix in ring-tailed lemurs. A review of the primate appendix by Fisher (2000) did not include the ring-tailed lemur as either a species with or without an appendix, and neither Campbell et al. (2000) nor McGrosky et al. (2019b) reported evidence for an appendix in ring-tailed lemurs. The external appearance of the caecum of some individuals included an apparent narrowing of the caecal apex that created the impression of an appendix (Fig. 2), but neither thickening of the mucosa nor macroscopic appearance of lymphatic tissue were evident (Fig. 3). A recent description of the gastrointestinal anatomy of another lemur species, Eulemur coronatus, also did not suggest the presence of an appendix (Schwitzer 2009), although the species is among those for which an appendix is assumed in the literature (Fisher 2000; Smith et al. 2013, 2017). A more detailed histological study of the putative appendices of lemur species might be interesting.

To conclude, the present study emphasizes that, even though comparative studies might have to work with species averages, one should not forget that biological features may show a large range of interindividual variability that does not necessarily lend itself to easy explanation. Across the different ontogenetic stages of L. catta examined in the present study, there is an indication both for a similar more-than-geometric (or positively allometric) scaling of gut length, and for a relative increase in tissue mass of those sections of the gastrointestinal tract where fermentation occurs with the dietary shift from milk to solid food, the caecum and the colon. Experimental approaches to organ preservation notwithstanding, the present study suggests that measurements of material preserved frozen-either as whole carcasses, or after dissection of the carcass-or of material preserved in formalin after dissection, can be equally used for a comparative study. We hope that the ease with which macroanatomical measurements can be taken, and the ubiquitous opportunity for this in the form of zoological institutions where animals live and die, will facilitate the establishment of updated datasets that can be used to test hypotheses ranging from those on physiology to evolutionary history.

Acknowledgements We thank the contributing zoological institutions for donating the material for scientific curation and the Japan Monkey Centre for facilitating the project and sharing their knowledge of the lemurs.

Author contributions MC, ACK, JS, and IM designed the study; MC, JT, NLA, ACK, GH, TT, YS, and IM performed the measurements; MC and IM analyzed the data; MC, JT, and NLA wrote the first draft of the manuscript that then received input from all the co-authors.

Funding Open access funding provided by University of Zurich. This study was partly financed by a Japan Society for the Promotion of Science KAKENHI grant (no. 19H03308, to I. M.). National Museums Scotland thanks the Negaunee Foundation for its generous support of a curatorial preparator.

Data availability The data set supporting this article has been uploaded as part of the supplementary material.

\section{Compliance with ethical standards}

Conflict of interest The authors declare no competing financial and/or non-financial interests in relation to the work described.

Ethical approval Because the material used in this study did not derive from animals killed for the purpose of this study, ethical approval was not required in Europe. This study (Japanese samples) was conducted in compliance with guidelines for the care and use of nonhuman primates by the Japan Monkey Centre.

Open Access This article is licensed under a Creative Commons Attribution 4.0 International License, which permits use, sharing, adaptation, distribution and reproduction in any medium or format, as long as you give appropriate credit to the original author(s) and the source, provide a link to the Creative Commons licence, and indicate if changes were made. The images or other third party material in this article are included in the article's Creative Commons licence, unless indicated otherwise in a credit line to the material. If material is not included in the article's Creative Commons licence and your intended use is not permitted by statutory regulation or exceeds the permitted use, you will need to obtain permission directly from the copyright holder. To view a copy of this licence, visit http://creativecommons.org/licenses/by/4.0/.

\section{References}

Brody SB (1945) Bioenergetics and growth with special reference to the efficiency complex in domestic animals. MacMillan, London

Calder WA (1996) Size, function and life history. Havard University Press, Cambridge

Campbell JL, Eisemann JH, Williams CV, Glenn KM (2000) Description of the gastrointestinal tract of five lemur species: Propithecus tattersalli, Propithecus verreauxi coquereli, Varecia variegata, Hapalemur griseus, and Lemur catta. Am J Primatol 52:133-142 
Clauss M, Hummel J (2005) The digestive performance of mammalian herbivores: why big may not be that much better. Mamm Rev 35:174-187

Crile G, Quiring DP (1940) A record of the body weight and certain organ and gland weights of 3690 animals. Ohio J Sci 40:219-259

Dauendorffer JN, Bastuji-Garin S, Guéro S, Brousse N, Fraitag S (2009) Shrinkage of skin excision specimens: formalin fixation is not the culprit. Br J Dermatol 160:810-814

Drea CM, Weil A (2008) External genital morphology of the ringtailed lemur (Lemur catta): females are naturally "masculinized." J Morphol 269:451-463

Fisher RE (2000) The primate appendix: a reassessment. Anat Rec 261:228-236

Godfrey NW (1961) The functional development of the calf. I. Growth of the stomach of the calf. J Agric Sci 57:173-175

Hume ID, Jazwinski E, Flannery TF (1993) Morphology and function of the digestive-tract in New Guinean possums. Aust J Zool $41: 85-100$

Koyama N et al (2008) Body mass of wild ring-tailed lemurs in Berenty Reserve, Madagascar, with reference to tick infestation: a preliminary analysis. Primates 49:9-15

Kripke SA, Fox AD, Berman JM, Settle RG, Rombeau JL (1989) Stimulation of intestinal mucosal growth with intracolonic infusion of short-chain fatty acids. J Parenter Enter Nutr 13:109-116

Lavin SR, Karasov WH, Ives AR, Middleton KM, Garland T (2008) Morphometrics of the avian small intestine compared with that of nonflying mammals: a phylogenetic approach. Physiol Biochem Zool 81:526-550

Lentle RG, Stafford KJ, Henderson IM (1997) The effect of formalin on rumen surfac area in red deer. Anat Histol Embryol 26:127-130

Lovegrove BG (2010) The allometry of rodent intestines. J Comp Physiol B 180:741-755

McGrosky A, Navarrete A, Isler K, Langer P, Clauss M (2016) Gross intestinal morphometry and allometry in Carnivora. Eur J Wildl Res 62:395-405

McGrosky A et al (2019a) Gross intestinal morphometry and allometry in ruminants. J Morphol 280:1254-1266

McGrosky A et al (2019b) Gross intestinal morphometry and allometry in primates. Am J Primatol 81:e23035

McKenney EA, O'Connell TM, Rodrigo A, Yoder AD (2018) Feeding strategy shapes gut metagenomic enrichment and functional specialization in captive lemurs. Gut Microbes 9:202-217

Navarrete A, van Schaik CP, Isler K (2011) Energetics and the evolution of human brain size. Nature 480:91-94

Naya DE, Bozinovic F, Karasov WH (2008) Latitudinal trends in digestive flexibility: testing the climatic variability hypothesis with data on the intestinal length of rodents. Am Nat 172:E122-E134

Nickel R (1933) Über die Ermittlung der Länge und Lage des Verdauungskanals. Z Ges Exp Med 91:193-243

Parker RR (1963) Effects of formalin on length and weight of fishes. J Fish Res Bd Can 20:1441-1455

Prothero JW (2015) The design of mammals. A scaling approach. Cambridge University Press, Cambridge
R Core Team (2017) R: a language and environment for statistical computing. version 3.4.1. R Foundation for Statistical Computing, Vienna, https://www.R-project.org/

Rasamimanana HR, Rafidinarivo E (1993) Feeding behavior of Lemur catta females in relation to their physiological state. Lemur social systems and their ecological basis. Springer, Boston, pp 123-133

Ridgway SH, Van Alstyne KR (2017) The blue whale brain misrepresented by an alcohol dehydrated brain of 3,636 grams. Mar Mamm Sci 33:386-388

Schwitzer C (2009) Gastrointestinal morphology of the crowned lemur (Eulemur coronatus). Anat Histol Embryol 38:429-431

Simmen B et al (2006) Plant species fed on by Lemur catta in gallery forests of the southern domain of Madagascar. Ringtailed lemur biology. Springer, Boston, pp 55-68

Simmen B, Bayart F, Rasamimanana H, Zahariev A, Blanc S, Pasquet P (2010) Total energy expenditure and body composition in two free-living sympatric lemurs. PLoS ONE 5:e9860

Smith HF, Parker W, Kotzé SH, Laurin M (2013) Multiple independent appearances of the cecal appendix in mammalian evolution and an investigation of related ecological and anatomical factors. C R Palevol 12:339-354

Smith HF, Parker W, Kotzé SH, Laurin M (2017) Morphological evolution of the mammalian cecum and cecal appendix. C R Palevol 16:39-57

Smyth GB (1988) Effects of age, sex, and post mortem interval on intestinal lengths of horses during development. Equine Vet $\mathrm{J}$ 20:104-108

Sussman RW (1991) Demography and social organization of freeranging Lemur catta in the Beza Mahafaly Reserve, Madagascar. Am J Phys Anthropol 84:43-58

Toloza EM, Diamond J (1992) Ontogenetic development of nutrient transporters in rat intestine. Am J Physiol 263:G593-G604

Underhill BM (1955) Intestinal length in man. Br Med J 2:1243-1246

Wardrop ID, Coombe JB (1960) The post-natal growth of the visceral organs of the lamb. I. The growth of the visceral organs of the grazing lamb from birth to sixteen weeks of age. J Agric Sci $54: 140-143$

Wołczuk K, Wilczyńska B, Jaroszewska M, Kobak J (2011) Morphometric characteristics of the small and large intestines of Mus musculus during postnatal development. Folia Morphol 70:252-259

Woodall PF, Skinner JD (1993) Dimensions of the intestine, diet and faecal water loss in some African antelope. J Zool 229:457-471

Zhou R, Orkin BA, Williams JM, Serici A, Poirier J (2020) In vivo small bowel length is longer than in formalin-fixed cadavers. Int J Surg Res Pract 7:107

Publisher's Note Springer Nature remains neutral with regard to jurisdictional claims in published maps and institutional affiliations.

\section{Affiliations}

\section{Marcus Clauss ${ }^{1}$ - Jelscha Trümpler ${ }^{1}$ - Nicole L. Ackermans ${ }^{1,8}$. Andrew C. Kitchener ${ }^{2}$. Georg Hantke ${ }^{2}$. Julia Stagegaard ${ }^{3} \cdot$ Tomo Takano $^{4} \cdot$ Yuta Shintaku ${ }^{4} \cdot$ Ikki Matsuda $^{4,5,6,7}$}

\author{
Jelscha Trümpler \\ jelscha.truempler@uzh.ch \\ Nicole L. Ackermans \\ nlackermans@gmail.com
}

\author{
Andrew C. Kitchener \\ a.kitchener@nms.ac.uk \\ Georg Hantke \\ g.hantke@nms.ac.uk
}


Julia Stagegaard

julia.stagegaard@ reepark.dk

Tomo Takano

tomo.takano@j-monkey.jp

Yuta Shintaku

shintaku.jmc@gmail.com

Ikki Matsuda

ikki.matsuda@gmail.com

1 Clinic for Zoo Animals, Exotic Pets and Wildlife, Vetsuisse Faculty, University of Zurich, Winterthurerstrasse 260, 8057 Zurich, Switzerland

2 Department of Natural Sciences, National Museums Scotland, Chambers Street, Edinburgh EH1 1JF, UK
3 Ree Park Safari, Stubbe Soevej 15, 8400 Ebeltoft, Denmark

4 Japan Monkey Centre, Inuyama, Japan

5 Chubu University Academy of Emerging Sciences, 1200, Matsumoto-cho, Kasugai, Aichi 487-8501, Japan

6 Wildlife Research Center, Kyoto University, Kyoto, Japan

7 Institute for Tropical Biology and Conservation, Universiti Malaysia Sabah, Kota Kinabalu, Sabah, Malaysia

8 Present Address: Center for Anatomy and Functional Morphology, Icahn School of Medicine at Mount Sinai, Annenberg Building, 1468 Madison Avenue, New York, NY 10029, USA 